\title{
Testes-specific protease 50 as an independent risk factor for poor prognosis in patients with non-small cell lung cancer
}

\author{
WEN-LIANG QIAO ${ }^{1 *}$, BO-WEN SHI ${ }^{1,2^{*}}$, YU-DONG HAN ${ }^{1}$, HUA-MEI TANG $^{3}$, \\ JUN LIN ${ }^{3}$, HAI-YANG HU ${ }^{1}$ and QIANG LIN ${ }^{1}$ \\ ${ }^{1}$ Department of Thoracic Surgery, Shanghai First People's Hospital, School of Medicine, \\ Shanghai Jiao Tong University, Shanghai 200080; ${ }^{2}$ Department of Thoracic Surgery, Changhai Hospital, \\ Second Military Medical University, Shanghai 200433; ${ }^{3}$ Department of Pathology, Shanghai First People's Hospital, \\ School of Medicine, Shanghai Jiao Tong University, Shanghai 200080, P.R. China
}

Received August 13, 2015; Accepted February 7, 2017

DOI: $10.3892 / \mathrm{ol} .2018 .8387$

\begin{abstract}
Testes-specific protease 50 (TSP50) is normally expressed in the testes and is overexpressed in various types of human cancers, including breast cancer, colorectal carcinoma and laryngocarcinoma. However, little has been reported on the association between TSP50 and non-small cell lung cancer (NSCLC). The present study aimed to detect TSP50 expression in 198 strict follow-up cases of paired NSCLC and 15 cases of normal lung parenchymal specimens using immunohistochemical staining. The expression levels of TSP50 were then correlated with the clinicopathological factors of NSCLC to assess its potential diagnostic and prognostic value. The relationship between TSP50 expression and the clinicopathological parameters of NSCLC was evaluated using $\chi^{2}$ and Fisher's exact tests. Survival rates for the overall population $(n=198)$ were calculated using the Kaplan-Meier method, and univariate and multivariate analyses were performed using the Cox's proportional hazards regression model. $\mathrm{P}<0.05$ was considered to indicate a statistically significant difference. The expression of TSP50 was significantly increased in NSCLC tissue compared with in adjacent non-tumor or normal lung parenchymal tissue $(\mathrm{P}<0.001)$. A significant association was revealed between high expression levels of TSP50 and clinicopathological characteristics including tumor differentiation $(\mathrm{P}=0.012)$, late tumor status $(\mathrm{P}=0.004)$ and late tumor node metastasis stage $(\mathrm{P}=0.026)$, as well as a reduced disease free survival $(\mathrm{P}=0.009)$ and overall survival rate $(\mathrm{P}=0.002)$ in all
\end{abstract}

Correspondence to: Dr Qiang Lin, Department of Thoracic Surgery, Shanghai First People's Hospital, School of Medicine, Shanghai Jiao Tong University, 100 Haining Road, Shanghai 200080, P.R. China

E-mail: xklinqiang@hotmail.com

*Contributed equally

Key words: testes-specific protease 50, non-small cell lung cancer, prognosis, survival analysis, cancer/testis antigens patients with NSCLC. Multivariate analyses demonstrated that high TSP50 expression in tumor tissues was significantly associated with a shorter disease-free survival rate [hazard ratio $(\mathrm{HR})=1.590,95 \%$ confidence interval $(\mathrm{CI}): 1.035-2.441]$, and with a shorter overall survival rate $(\mathrm{HR}=1.814 ; 95 \% \mathrm{CI}$ : 1.156-2.846). In conclusion, the present data demonstrated that increased TSP50 protein expression may be a potential predictor of early recurrence and poor prognosis in NSCLC, and that TSP50 expression levels possess the potential to be used as a biomarker and therapeutic target for the treatment of patients with NSCLC.

\section{Introduction}

Lung cancer is the most common cause of cancer-associated mortality worldwide, and non-small cell lung cancer (NSCLC) accounts for $\sim 85 \%$ of all types of lung cancer (1). Although lung cancer mortality has decreased by $\sim 16-20 \%$ as a result of screening with low-dose computed tomography compared with standard chest $\mathrm{x}$-ray, the majority of lung cancer remains diagnosed at an advanced stage and frequently has a poor prognosis (2). Mortality often occurs even in patients with early-stage lung cancer as a result of recurrent disease and distant metastases following curative surgical resection. The long-term survival rate for patients with lung cancer remains low (3). Consequently, prognostic markers other than the TNM staging system (4) are necessary in order to improve the prognosis of patients with NSCLC who have received treatment.

Testes-specific protease 50 (TSP50) is a testis-specific gene, which encodes a protease-like protein, and is normally specifically expressed in the spermatocytes of human testes and is involved in spermatogenesis $(5,6)$. However, a previous study has observed it to be abnormally activated and expressed in the majority of breast cancer epithelial cells (6). This abnormal activation and expression has been associated with the putative p53-binding site and several Sp1-binding sites on the TSP50 promoter, which means that the TSP50 gene maybe negatively regulated by the $p 53$ gene (7). Additional studies have demonstrated that the overexpression of TSP50 promotes cellular proliferation and tumorigenesis depending on activation of the nuclear factor- $\kappa \mathrm{B}(\mathrm{NF}-\kappa \mathrm{B})$ 
signaling pathway, by binding to the NF- $\kappa \mathrm{B}-$ nuclear factor of $\kappa$ light polypeptide gene enhancer in B-cells inhibitor $\alpha$ $(\mathrm{I} \kappa \mathrm{B} \alpha)$ complex. This in turn promotes cellular invasion and metastasis by increasing NF- $\kappa \mathrm{B}$ dependent matrix metalloproteinase-9 (MMP9) expression, thus TSP50 and MMP9 have been associated with increased rates of metastasis and poorer survival rate of patients with breast cancer $(8,9)$. In addition, an increasing number of studies have reported that TSP50 is involved in the progression of other malignant tumors, including colorectal carcinoma, gastric and cervical cancer (10-12). In conclusion, these aforementioned results imply that the TSP50 gene may be an oncogene.

Despite the increasing number of studies demonstrating that TSP50 is involved in tumorgenesis in various different types of cancer, the expression state of the TSP50 gene in NSCLC remains unknown. The present study therefore aimed to examine the status of the TSP50 protein in specimens of human NSCLC. The clinicopathological and prognostic significance of TSP50 expression for patients with NSCLC was also assessed.

\section{Materials and methods}

Patients and tissue samples. The present retrospective study randomly selected NSCLC specimens paired with adjacent non-tumorous tissues and normal lung tissues from patients who had undergone surgical resection for lung cancer at The First People's Hospital of Shanghai Jiao Tong University (Shanghai, China), between January 2006 and January 2011. The exclusive criteria were as follows: Patients who died within 1 month of surgery; patients with history of second primary tumor; and patients who received neoadjuvant chemotherapy or radiotherapy. During the study period, tissues from 355 patients who underwent surgical resection at The First People's Hospital of Shanghai Jiao Tong University were available. In total, 21 cases were excluded due to samples being too small to detect immunohistochemical staining, 97 were excluded due to incomplete survival rate data and 39 were excluded according to the exclusion criteria described above. Therefore, a total of 198 patients were enrolled in the present retrospective study, and the clinical follow-up duration of the patients ranged between 2.5 and 98.1 months. The present study was approved by the Ethics Committee of Shanghai Jiao Tong University School of Medicine (Shanghai, China) and informed consent was obtained from each patient prior to surgery.

Surgical specimens were fixed in $4 \%$ neutral-buffered formaldehyde at room temperature for $24 \mathrm{~h}$, and processed for histopathological and immunohistochemical evaluation. Clinicopathological factors including age, sex, smoking history, extent of tumor differentiation, visceral pleural invasion, T status lymphatic invasion and TNM stage were reviewed for all above cases. The treatment of patients (surgical procedure and adjuvant therapy) was also reviewed. Histological diagnosis and grade of differentiation of the tumors were determined by hematoxylin and eosin staining according to the World Health Organization criteria (13) and pathological stage were classified according to the 7 th edition of the American Joint Committee on Cancer (4). All stage IIA or higher patients and high-risk stage IB patients with poorly differentiated tumors or incomplete lymph node resection had received platinum-based adjuvant chemotherapy or radiotherapy.

Immunohistochemistry.Formalin-fixedandparaffin-embedded tissue blocks were cut into sections of $\sim 3-4 \mu \mathrm{m}$ thickness. Paraffin sections were routinely deparaffinized with dimethylbenzene after heated at $60^{\circ} \mathrm{C}$ for $2.5 \mathrm{~h}$, rehydrated with a graded alcohol series of $100,90,80$ and $70 \%$ concentrations for 5 min separately and heated for antigen retrieval with $0.01 \mathrm{~mol} / 1$ citrate buffer solution $(\mathrm{pH} 6.0)$ for $25 \mathrm{~min}$ at $95^{\circ} \mathrm{C}$ in a microwave oven, and allowed to cool for $60 \mathrm{~min}$ at room temperature. Endogenous peroxidase was blocked in $3 \% \mathrm{H}_{2} \mathrm{O}_{2}$ solution for $10 \mathrm{~min}$ at $37^{\circ} \mathrm{C}$. Slides were subsequently blocked with $10 \%$ normal goat serum (cat. no. AR0004; Wuhan Boster Biological Technology, Ltd., Wuhan, China) at room temperature for $10 \mathrm{~min}$ and incubated overnight at $4^{\circ} \mathrm{C}$ with the primary rabbit polyclonal antibody against TSP50 (dilution, 1:150; cat. no. 12574-1-AP; ProteinTech Group, Inc., Chicago, IL, USA). Slides with PBS served as parallel negative controls and breast cancer sections incubated with the TSP50 antibody were used as positive controls. Subsequent to five washing steps with PBS ( $\mathrm{pH}$ 7.4), slides were incubated with goat anti-rabbit second antibody conjugated with streptavidin-biotin peroxidase (dilution, 1:1,000; cat. no. SA1052; Wuhan Boster Biological Technology, Ltd.) at $37^{\circ} \mathrm{C}$ for $20 \mathrm{~min}$ and visualized with 3,3-diaminobenzidine. The sections were then counterstained with hematoxylin, washed with tap water and dehydrated with ethanol washes of 1 min each at increasing concentrations of $75,80,90$ and $100 \%$.

Evaluation of immunohistochemical staining. Two experienced pathologists who were blind to clinical information independently evaluated all TSP50 stained slides. Staining intensities of individual cells were graded as follows: 0 , no staining; 1 , weak; 2 , medium; and 3 , strong. The percentages of positive tumor cells in the field were calculated as follows: Score 0 , negative staining; score $1,0-10 \%$; score $2,10-50 \%$; score $3,51-75 \%$; and score $4,75-100 \%$. The final score was the sum of the staining intensity score and percentage staining score. The final scores were then defined as: 0 , negative expression; 1-3, weakly positive expression; 4-5, moderate expression; and 6-7, strong positive expression. The scores from all NSCLC samples were then divided into two groups: Low expression (scores 0-3); and high expression (scores 4-7).

Assessment and imaging of IHC was performed using a Leica DM6000B light microscope equipped with Leica DFC Cameras-Image Acquisition System software [version 4.5.0; Leica Microsystems (Schweiz) AG, Heerbrugg, Switzerland].

Statistical analysis. Disease free survival (DFS) was defined as the time from surgical resection to recurrence, and overall survival (OS) as the time from surgical resection to mortality relative to disease recurrence. Associations between TSP50 protein expression and clinicopathological parameters were assessed using the Pearson's $\chi^{2}$ test or Fisher's exact test for the categorical variables. To analyze the follow-up data, DFS and OS curves were generated using the Kaplan-Meier method and differences in survival curves was analyzed using the log-rank test. Multivariate analysis was performed 
using the Cox's proportional hazards regression model on all significant characteristics determined from univariate analysis. $\mathrm{P}<0.05$ was considered to indicate a statistically significant difference. All statistical analyses were performed using SPSS software version 21.0 for Windows (IBM SPSS, Armonk, NY, USA).

\section{Results}

Patients clinical characteristics. Among the 198 patients, 110 were males and 88 were females, with a mean age of $66.3 \pm 10.19$ years (range, 22-80 years), and 95 patients were current or former smokers while 103 patients had never smoked. In total, 116 patients (59\%) were classified as having early stage NSCLC (stage I or II) and 82 patients (41\%) were classified as advanced stage (stage III and IV). A total of 81 patients (41\%) had positive lymph nodes, 53 patients (27\%) were staged as T3 or T4, 64 (32\%) had well-differentiated tumors and 98 (50\%) had moderately-differentiated tumors. A total of 90 patients $(45 \%)$ were positive for visceral pleural invasion, and 124 patients (63\%) received adjuvant chemotherapy or radiotherapy subsequent to surgery. All specimens consisted of 106 patients with adenocarcinoma (54\%) and 92 patients with non-adenocarcinoma (46\%; 77 squamous carcinoma and 15 adenosquamous carcinoma). The specific clinical characteristics of patients included in the present study are summarized in Table I.

TSP50 is highly expressed in NSCLC. The present study detected 198 cases of paraffin-embedded NSCLC with matched adjacent non-tumor tissues, as well as 15 cases of paraffin-embedded normal lung tissues via immunohistochemical staining. Stained cells were recognized as positive when cytoplasmic staining was identified. The low expression (negative and weak protein expression combined) rate of TSP50 in NSCLC tissues was $61 \%$. Meanwhile, the high expression (moderate and strong protein expression combined) rate of TSP50 in NSCLC tissues was 39\% (Table II), which was significantly increased compared with the rates in either adjacent non-tumor or normal lung tissues, respectively $(\mathrm{P}<0.001$; Fig. 1, Table II $)$.

Association between TSP50 expression and clinicopathological characteristics. The association between TSP50 expression and the clinicopathological characteristics of patients with NSCLC is summarized in Table I. The results demonstrated that the expression of TSP50 was correlated with tumor differentiation $(\mathrm{P}=0.012)$, and that high expression of TSP50 was more frequent among poorly differentiated tumors compared with well or moderately differentiated tumors [18 and $32(\mathrm{P}=0.003), 18$ and 50\% $(\mathrm{P}=0.033)$, respectively]. In addition, high expression of TSP50 was more frequently observed in advanced stage (III and IV) samples compared with early stage (I and II) specimens (41 and 59\%, respectively; $\mathrm{P}=0.026$ ). Similar results were observed for tumor status, with high expression levels of TSP50 more frequently observed in late tumor status (T3+T4) compared with in early tumor status $(\mathrm{T} 1+\mathrm{T} 2)$ specimens (54 and $32 \%$, respectively; $\mathrm{P}=0.004)$. However, the Pearson's $\chi^{2}$ test and Fisher's exact test identified no significant association between TSP50 expression and age, sex, smoking history, visceral pleural invasion, lymphatic invasion, surgical procedure, histological types or adjuvant therapy.

TSP50 high-level expression predicts poor survival rates in NSCLC patients. To investigate the prognostic value of TSP50 expression in NSCLC, the present study constructed a survival curve via the Kaplan-Meier method and analyzed the association between TSP50 expression and patient survival rate using the log-rank test. It was revealed that patients with high TSP50 expression had lower DFS (log-rank=6.876, $\mathrm{P}=0.009)$ and $\mathrm{OS}(\log -\mathrm{rank}=9.609, \mathrm{P}=0.002)$ rates compared within patients with low TSP50 expression (Fig. 2A and B, respectively).

TSP50 is an independent prognostic factor in SCLC via the Cox's proportional hazards regression model. The median DFS for all study patients was 38.0 months. By univariate analysis, it was identified that in patients with NSCLC, a poorer DFS was associated with smoking history $(\mathrm{HR}=1.592$, $\mathrm{P}=0.031)$, lymph node metastasis $(\mathrm{HR}=1.658, \mathrm{P}=0.019)$ and an advanced (III and IV) TNM stage (HR=1.649, P=0.021). In addition, high TSP50 expression was significantly associated with a poorer DFS (33.7 vs. 41.0 months, $\mathrm{HR}=1.751, \mathrm{P}=0.010$ ). Multivariate survival analysis was performed using the Cox's proportional hazards regression model for all significant variables in the univariate survival analysis. This multivariate analysis revealed that smoking history $(\mathrm{HR}=1.548$, $\mathrm{P}=0.044)$, lymph node invasion $(\mathrm{HR}=1.587, \mathrm{P}=0.033)$, TNM stage $(\mathrm{HR}=1.610, \mathrm{P}=0.030)$ and TSP50 expression $(\mathrm{HR}=1.590$, $\mathrm{P}=0.034)$ were independent prognostic indicators of DFS for patients with NSCLC (Table III).

The median OS for all study subjects was 42.3 months. Univariate analysis demonstrated that late tumor status (T3+T4; $\mathrm{HR}=1.651, \mathrm{P}=0.037)$, lymph node metastasis $(\mathrm{HR}=1.889$, $\mathrm{P}=0.005$ ), advanced stage (III and IV; $\mathrm{HR}=2.119, \mathrm{P}=0.001$ ), and high TSP50 expression ( 38.2 vs. $45.2, \mathrm{P}=0.002)$ were significantly associated with poorer OS. Additional multivariate analysis demonstrated that lymph node invasion $(\mathrm{HR}=1.849$, $\mathrm{P}=0.007)$, TNM stage $(\mathrm{HR}=1.975, \mathrm{P}=0.003)$ and TSP50 expression $(\mathrm{HR}=1.814, \mathrm{P}=0.010)$ proved to be independent prognostic indicators of OS for NSCLC patients (Table IV).

\section{Discussion}

TSP50 is a human testis-specific gene, which encodes a 50-kDa serine (Ser) protease-like protein, and was isolated from a fragment of hypomethylated DNA from human breast cancer cells using the methylation sensitive representational difference analysis technique (14). Although the TSP50 gene product shares a similar enzymatic structure with numerous Ser proteases, it is possible to classify it as a novel protease for its two critical catalytic triads, which have a substitution of threonine (Thr) at the Ser residue site, which makes it different from traditional Ser proteases $(5,15,16)$. Normally, TSP50 is expressed only in germ cells in human testes and is overexpressed in different types of human cancers, including breast and cervical cancer and laryngocarcinoma (17). Currently, TSP50 is also considered to be a cancer/testis antigen (CTA), which are immunogenic proteins (18). CTAs are a large family of $\sim 140$ members, a 
Table I. TSP50 expression and clinicopathological parameters of NSCLC cases.

\begin{tabular}{|c|c|c|c|c|}
\hline \multirow[b]{2}{*}{ Characteristics } & \multirow[b]{2}{*}{$\begin{array}{c}\text { No. of } \\
\text { patients (\%) }\end{array}$} & \multicolumn{2}{|c|}{ TSP50 expression (\%) } & \multirow[b]{2}{*}{ P-value } \\
\hline & & $\begin{array}{c}\text { Low expression } \\
\text { (negative and weak) }\end{array}$ & $\begin{array}{l}\text { High expression } \\
\text { (medium and strong) }\end{array}$ & \\
\hline Total & $198(100)$ & $122(62)$ & $76(38)$ & \\
\hline Age, years & & & & 0.367 \\
\hline$<60$ & $73(37)$ & $42(22)$ & $31(15)$ & \\
\hline$>60$ & $125(63)$ & $80(40)$ & $45(23)$ & \\
\hline Sex & & & & 0.414 \\
\hline Male & $110(56)$ & $65(33)$ & $45(23)$ & \\
\hline Female & $88(44)$ & $57(29)$ & $31(15)$ & \\
\hline Smoking history & & & & 0.301 \\
\hline Smoker & $95(48)$ & $55(28)$ & $40(20)$ & \\
\hline Never smoked & $103(52)$ & $67(34)$ & $36(18)$ & \\
\hline Tumor differentiation & & & & 0.012 \\
\hline Well & $64(32)$ & $46(23)$ & $18(9)$ & \\
\hline Moderately & $98(50)$ & $61(31)$ & $37(19)$ & \\
\hline Poorly & $36(18)$ & $15(8)$ & $21(10)$ & \\
\hline Visceral pleural invasion & & & & 0.455 \\
\hline Absent & $90(45)$ & $58(29)$ & $32(16)$ & \\
\hline Present & $108(55)$ & $64(33)$ & $44(22)$ & \\
\hline T status & & & & 0.004 \\
\hline $\mathrm{T} 1+\mathrm{T} 2$ & $145(73)$ & $98(50)$ & $47(23)$ & \\
\hline $\mathrm{T} 3+\mathrm{T} 4$ & $53(27)$ & $24(12)$ & $29(15)$ & \\
\hline Lymphatic invasion & & & & 0.245 \\
\hline Positive & $81(41)$ & $46(24)$ & $35(17)$ & \\
\hline Negative & $117(59)$ & $76(38)$ & $41(21)$ & \\
\hline TNM stage & & & & 0.026 \\
\hline $\mathrm{I}+\mathrm{II}$ & $116(59)$ & $79(40)$ & $37(19)$ & \\
\hline $\mathrm{III+IV}$ & $82(41)$ & $43(22)$ & $39(19)$ & \\
\hline Surgical procedure & & & & 0.196 \\
\hline Pneumonectomy & $11(6)$ & $6(3)$ & $5(3)$ & \\
\hline Lobectomy & $125(63)$ & $83(42)$ & $42(21)$ & \\
\hline Wedge resection & $62(31)$ & $33(17)$ & $29(14)$ & \\
\hline Histological types & & & & 0.431 \\
\hline $\mathrm{ADC}$ & $106(54)$ & $68(35)$ & $38(19)$ & \\
\hline Non-adenocarcinoma & $92(46)$ & $54(27)$ & $38(19)$ & \\
\hline Adjuvant therapy & & & & 0.277 \\
\hline Yes & $124(63)$ & $80(41)$ & $44(22)$ & \\
\hline No & $74(37)$ & $42(21)$ & $32(16)$ & \\
\hline
\end{tabular}

Statistical analyses were performed using Pearson's $\chi^{2}$ test. TSP50, testes-specific protease 50; NSCLC, non-small cell lung cancer; T, tumor; N, lymph node; M, metastasis; ADC, adenocarcinoma; non-adenocarcinoma, includes squamous cell carcinoma and adenosquamous carcinoma.

number of which have been reported to be overexpressed in lung cancer, including melanoma-associated antigen (MAGE)-3, NY-SAR-35, NY-ESO-1, MAGE-1, cancer testis-7, cancer/testis antigen 2 and MAGE-10 (19,20). Grah et al (21) reported that a statistically higher immunohistological expression rate of MAGE-A3/4 was observed in squamous cell carcinoma. The aforementioned study also revealed that there was a statistically significant correlation between MAGE-1 expression in adenocarcinoma and the presence of tumor necrosis and a significant correlation between NY-ESO-1 expression and positive lymph nodes in adenocarcinoma (21).

As little has been reported regardingTSP50 expression in patients with NSCLC, the present study performed IHC staining of 198 NSCLC specimens and revealed that 
Table II. TSP50 immunohistochemical staining for protein expression in NSCLC, adjacent non-tumorous and normal tissues.

\begin{tabular}{|c|c|c|c|c|c|c|}
\hline \multirow[b]{2}{*}{ Tissue sample } & \multirow[b]{2}{*}{ No. of cases } & \multicolumn{4}{|c|}{ TSP50 protein expression } & \multirow[b]{2}{*}{ P-value } \\
\hline & & Negative (\%) & Weak (\%) & Medium (\%) & Strong $(\%)$ & \\
\hline NSCLC tissues & 198 & $64(32)$ & $58(29)$ & $61(31)$ & $15(8)$ & $<0.001$ \\
\hline Adjacent non-tumor & 198 & 177 (89) & $19(10)$ & $2(1)$ & $0(0)$ & \\
\hline Normal lung tissues & 15 & $15(100)$ & $0(0)$ & $0(0)$ & $0(0)$ & \\
\hline
\end{tabular}

P-value is based on Pearson's $\chi^{2}$ test. TSP50, testes-specific protease 50; NSCLC, non-small cell lung cancer. P-value, NSCLC compared with adjacent non-tumor.

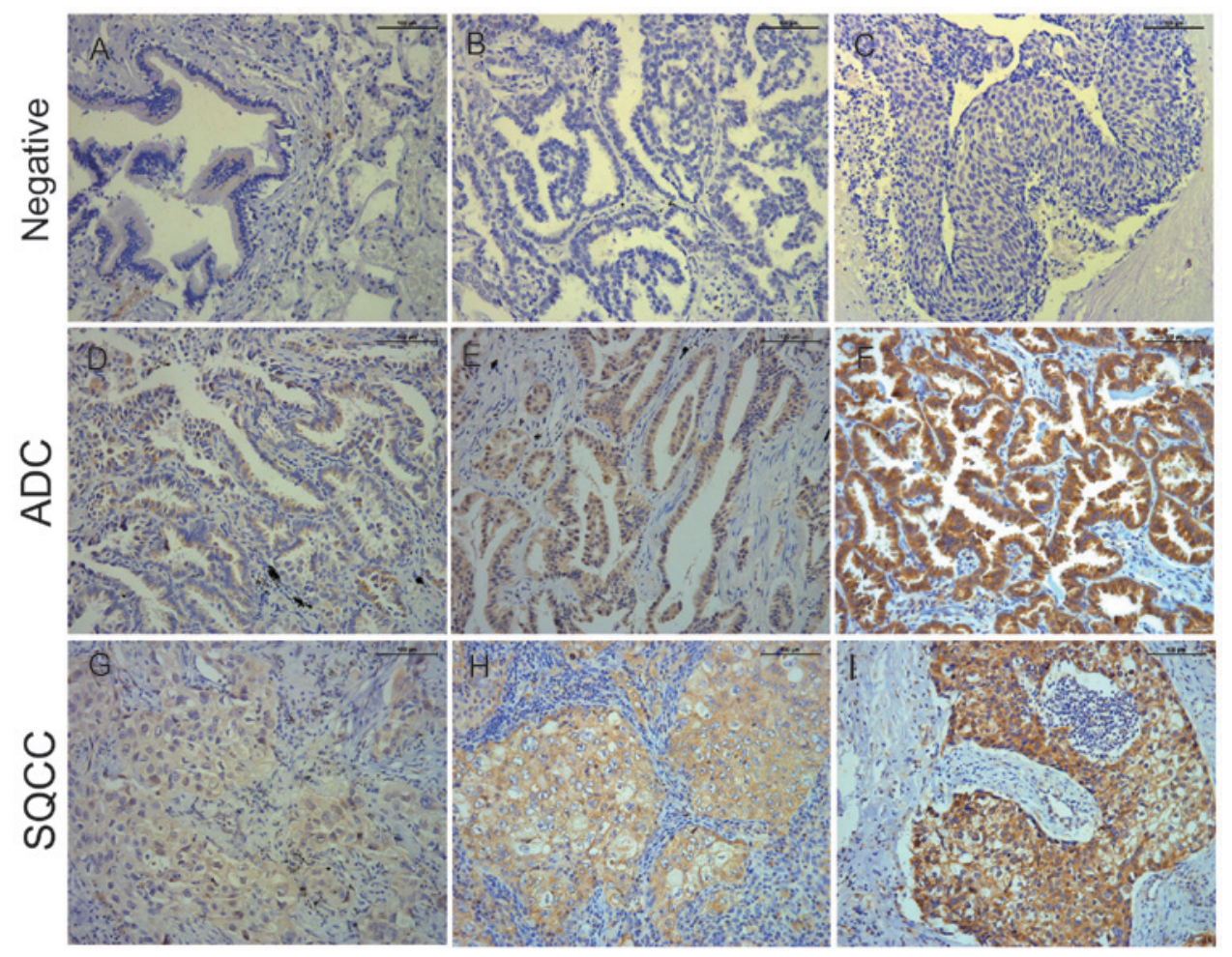

Figure 1. Immunohistochemical staining of TSP50 in non-cancerous or cancerous tissues of the human lung (magnification, x200). TSP50 was primarily detected in the cytoplasm of adenocarcinoma and squamous cell carcinoma tissues. Negative TSP50 expression in (A) normal bronchial epithelial, (B) adenocarcinoma and (C) squamous cell carcinoma tissues. (D) Weak, (E) medium and (F) strong TSP50 expression in ADC tissues. (G) Weak, (H) medium and (I) strong TSP50 expression in SQCC tissues. Scale bar, $100 \mu \mathrm{M}$. TSP50, testes-specific protease 50; ADC, adenocarcinoma; SQCC, squamous cell carcinoma.
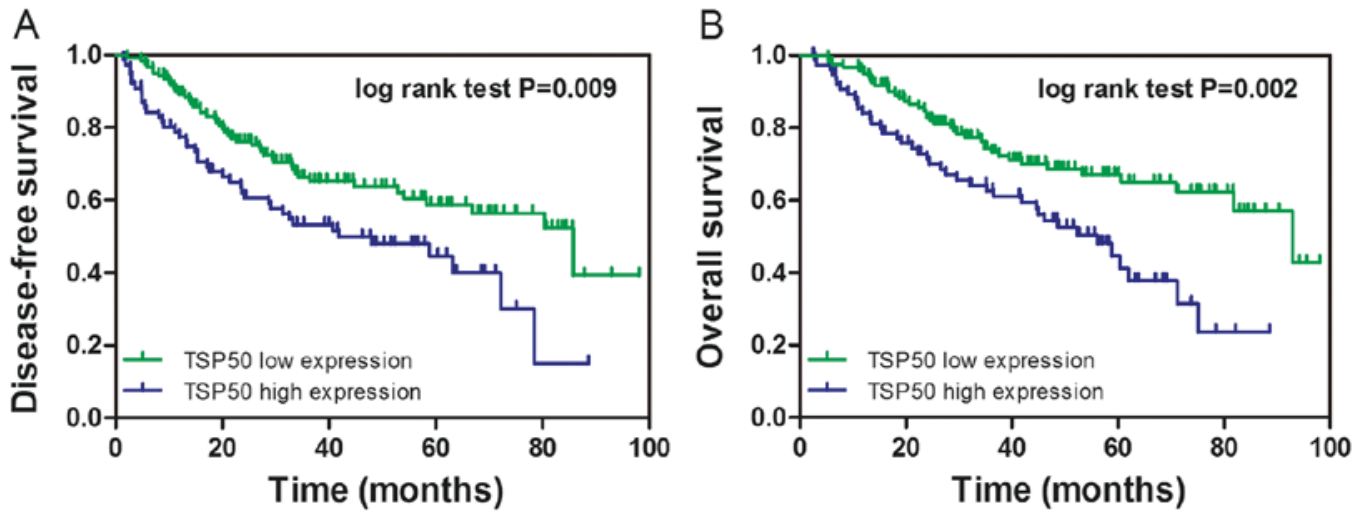

Figure 2. Kaplan-Meier analysis of the cumulative (A) DFS and (B) OS rates of all patients ( $\mathrm{n}=198)$ by TSP50 expression levels. DFS and OS were significantly lower in patients with TSP50 high expression tumors compared with in those with low TSP50 expression. TSP50, testes-specific protease 50; DFS, disease free survival; OS, overall survival. 
Table III. Univariate and multivariate Cox's proportional hazard models for DFS.

\begin{tabular}{|c|c|c|c|c|c|c|}
\hline \multirow[b]{2}{*}{ Characteristics } & \multirow[b]{2}{*}{$\begin{array}{c}\text { No. of } \\
\text { patients }(\%)\end{array}$} & \multicolumn{5}{|c|}{ Disease-free survival (DFS) } \\
\hline & & $\begin{array}{l}\text { Median DFS } \\
\text { (months) }\end{array}$ & $\begin{array}{c}\text { Univariate } \\
\text { analysis adjusted } \\
\text { HR }(95 \% \mathrm{CI})\end{array}$ & $\begin{array}{l}\text { Univariate } \\
\text { analysis } \\
\text { P-value }\end{array}$ & $\begin{array}{c}\text { Multivariate } \\
\text { analysis adjusted } \\
\text { HR }(95 \% \text { CI })\end{array}$ & $\begin{array}{c}\text { Multivariate } \\
\text { analysis } \\
\text { P-value }\end{array}$ \\
\hline All & $198(100)$ & 38.0 & & & & \\
\hline Age, years & & & & 0.455 & & NA \\
\hline$<60$ & $73(37)$ & 36.2 & $0.848(0.551-1.306)$ & & NA & \\
\hline$>60$ & $125(63)$ & 39.1 & & & & \\
\hline Sex & & & & 0.167 & & NA \\
\hline Male & $110(56)$ & 35.9 & $1.354(0.881-2.079)$ & & NA & \\
\hline Female & $88(44)$ & 40.7 & & & & \\
\hline Smoking history & & & & 0.031 & & 0.044 \\
\hline Smoker & $95(48)$ & 34.5 & $1.592(1.043-2.430)$ & & $1.548(1.011-2.370)$ & \\
\hline Never smoked & $103(52)$ & 41.2 & & & & \\
\hline Tumor differentiation & & & & 0.059 & & NA \\
\hline Well & $64(32)$ & 39.7 & $0.751(0.558-1.011)$ & & NA & \\
\hline Moderately & $98(50)$ & 37.1 & & & & \\
\hline Poorly & $36(18)$ & 37.5 & & & & \\
\hline Visceral pleural invasion & & & & 0.586 & & NA \\
\hline Absent & $90(45)$ & 39.1 & $1.125(0.736-1.719)$ & & NA & \\
\hline Present & $108(55)$ & 37.5 & & & & \\
\hline T status & & & & 0.067 & & NA \\
\hline $\mathrm{T} 1+\mathrm{T} 2$ & $145(73)$ & 39.5 & $1.523(0.972-2.387)$ & & NA & \\
\hline $\mathrm{T} 3+\mathrm{T} 4$ & $53(27)$ & 34.8 & & & & \\
\hline Lymphatic invasion & & & & 0.019 & & 0.033 \\
\hline Positive & $81(41)$ & 32.9 & $1.658(1.087-2.530)$ & & $1.587(1.038-2.424)$ & \\
\hline Negative & $117(59)$ & 41.9 & & & & \\
\hline TNM stage & & & & 0.021 & & 0.030 \\
\hline $\mathrm{I}+\mathrm{II}$ & $116(59)$ & 40.5 & $1.649(1.078-2.522)$ & & $1.610(1.047-2.474)$ & \\
\hline $\mathrm{III}+\mathrm{IV}$ & $82(41)$ & 35.0 & & & & \\
\hline Surgical procedure & & & & 0.145 & & NA \\
\hline Pneumonectomy & $11(6)$ & 45.2 & $0.753(0.514-1.103)$ & & NA & \\
\hline Lobectomy & $125(63)$ & 39.1 & & & & \\
\hline Wedge resection & $62(31)$ & 35.9 & & & & \\
\hline Histological types & & & & 0.295 & & NA \\
\hline $\mathrm{ADC}$ & $106(54)$ & 39.2 & $0.798(0.524-1.216)$ & & & \\
\hline Non-adenocarcinoma & $92(46)$ & 36.7 & & & NA & \\
\hline Adjuvant therapy & & & & 0.338 & & \\
\hline No & $124(63)$ & 40.4 & $1.244(0.796-1.944)$ & & NA & NA \\
\hline Yes & $74(37)$ & 37.0 & & & & \\
\hline TSP50 expression & & & & 0.010 & & 0.034 \\
\hline Low & $122(62)$ & 41.0 & $1.751(1.146-2.677)$ & & $1.590(1.035-2.441)$ & \\
\hline High & $76(38)$ & 33.7 & & & & \\
\hline
\end{tabular}

DFS, disease free survival; HR, hazard ratio; CI, confidence interval; T, tumor; N, lymph node; M, metastasis; Non-adenocarcinoma, including squamous cell carcinoma and adenosquamous carcinoma; TSP50, testes-specific protease 50.

the expression rate of the TSP50 protein was significantly increased compared with either adjacent non-tumor or normal lung tissues, suggesting that TSP50 may function as an oncogene and may be involved in the progression of 
Table IV. Univariate and multivariate Cox's proportional hazard models for OS.

\begin{tabular}{|c|c|c|c|c|c|c|}
\hline \multirow[b]{2}{*}{ Characteristics } & \multirow[b]{2}{*}{$\begin{array}{c}\text { No. of } \\
\text { patients }(\%)\end{array}$} & \multicolumn{5}{|c|}{ OS } \\
\hline & & $\begin{array}{c}\text { Median OS } \\
\text { (months) }\end{array}$ & $\begin{array}{c}\text { Univariate } \\
\text { analysis adjusted } \\
\text { HR }(95 \% \mathrm{CI})\end{array}$ & $\begin{array}{l}\text { Univariate } \\
\text { analysis } \\
\text { P-value }\end{array}$ & $\begin{array}{c}\text { Multivariate } \\
\text { analysis adjusted } \\
\text { HR }(95 \% \text { CI })\end{array}$ & $\begin{array}{c}\text { Multivariate } \\
\text { analysis } \\
\text { P-value }\end{array}$ \\
\hline All & $198(100)$ & 42.3 & & & & \\
\hline Age, years & & & & 0.521 & & NA \\
\hline$<60$ & $73(37)$ & 40.0 & $0.862(0.547-1.358)$ & & NA & \\
\hline$>60$ & $125(63)$ & 43.7 & & & & \\
\hline Sex & & & & 0.177 & & NA \\
\hline Male & $110(56)$ & 40.0 & $1.363(0.869-2.139)$ & & NA & \\
\hline Female & $88(44)$ & 45.6 & & & & \\
\hline Smoking history & & & & 0.058 & & NA \\
\hline Smoker & $95(48)$ & 38.6 & $1.535(0.985-2.391)$ & & NA & \\
\hline Never smoked & $103(52)$ & 45.7 & & & & \\
\hline Tumor differentiation & & & & 0.311 & & NA \\
\hline Well & $64(32)$ & 44.6 & & & & \\
\hline Moderately & $98(50)$ & 41.1 & $0.851(0.623-1.162)$ & & NA & \\
\hline Poorly & $36(18)$ & 41.5 & & & & \\
\hline Visceral pleural invasion & & & & 0.067 & & NA \\
\hline Absent & $90(45)$ & 44.1 & $1.536(0.971-2.430)$ & & NA & \\
\hline Present & $108(55)$ & 41.3 & & & & \\
\hline T status & & & & 0.037 & & 0.965 \\
\hline $\mathrm{T} 1+\mathrm{T} 2$ & $145(73)$ & 44.1 & $1.651(1.032-2.641)$ & & $1.012(0.604-1.695)$ & \\
\hline $\mathrm{T} 3+\mathrm{T} 4$ & $53(27)$ & 38.3 & & & & \\
\hline Lymphatic invasion & & & & 0.005 & & 0.007 \\
\hline Positive & $81(41)$ & 36.6 & $1.889(1.213-2.942)$ & & $1.849(1.186-2.884)$ & \\
\hline Negative & $117(59)$ & 46.6 & & & & \\
\hline TNM stage & & & & 0.001 & & 0.003 \\
\hline $\mathrm{I}+\mathrm{II}$ & $116(59)$ & 45.1 & $2.119(1.351-3.324)$ & & $1.975(1.255-3.108)$ & \\
\hline III + IV & $82(41)$ & 39.0 & & & & \\
\hline Surgical procedure & & & & 0.378 & & NA \\
\hline Pneumonectomy & $11(6)$ & 47.7 & & & NA & \\
\hline Lobectomy & $125(63)$ & 43.8 & $0.834(0.556-1.249)$ & & & \\
\hline Wedge resection & $62(31)$ & 40.0 & & & & \\
\hline Histological types & & & & 0.275 & & NA \\
\hline ADC & $106(54)$ & 43.8 & $0.782(0.503-1.216)$ & & NA & \\
\hline Non-adenocarcinoma & $92(46)$ & 40.7 & & & & \\
\hline Adjuvant therapy & & & & 0.256 & & NA \\
\hline No & $124(63)$ & 43.8 & $1.317(0.819-2.118)$ & & NA & \\
\hline Yes & $74(37)$ & 41.8 & & & & \\
\hline TSP50 expression & & & & 0.002 & & 0.010 \\
\hline Low & $122(62)$ & 45.2 & $1.999(1.279-3.124)$ & & $1.814(1.156-2.846)$ & \\
\hline High & $76(38)$ & 38.2 & & & & \\
\hline
\end{tabular}

OS, overall survival; HR, hazard ratio; CI, confidence interval; T, tumor; N, lymph node; M, metastasis; ADC, adenocarcinoma; non-adenocarcinoma, including squamous cell carcinoma and adenosquamous carcinoma; TSP50, testes-specific protease 50.

NSCLC. Although weak and medium expression of TSP50 was observed in certain adjacent non-tumorous tissues in the present study, a possible explanation for this discrepancy is that these adjacent non-tumorous tissues belong to atypical hyperplasia tissues, the extent of which may determine the irrelative low-level expression. In addition, the present study 
analyzed the relationship between TSP50 expression and clinicopathological features of patients with NSCLC and identified that high-level TSP50 expression was significantly correlated with poor tumor differentiation $(\mathrm{P}=0.012)$, late tumor status $(\mathrm{P}=0.004)$ and a late pathologic stage $(\mathrm{P}=0.026)$. In contrast, no relationship was identified between the expression of TSP50 and other clinical factors, including age, sex, smoking history, visceral pleural invasion, lymphatic invasion location subtype or surgical procedure, histological types and adjuvant therapy $(\mathrm{P}>0.05)$. These results confirmed that TSP50, as with other CTAs, is involved in NSCLC progression and metastasis. In addition, the results of the present study were also consistent with previous findings that suggested TSP50 as a potential oncogene, which has elevated expression levels in numerous other types of cancer.

Liu et al (11) and Zheng et al (10) reported that high expression levels of TSP50 are associated with more aggressive malignancy and poor prognosis in human gastric cancer and colorectal carcinoma, particularly for patients with early-stage colorectal carcinoma tumors. Grah et al (21) observed that there was a significantly improved survival rate in patients with adenocarcinoma who had positive expression of the CTA MAGE-A3/4 $(\mathrm{P}=0.012)$. With regard to survival rate, the present study also observed that patients with NSCLC with high-level TSP50 expression had lower DFS $(\mathrm{P}=0.009)$ and $\mathrm{OS}$ rates $(\mathrm{P}=0.002)$ compared with patients with low-level TSP50 expression. Although subgroup analysis failed to reveal a significant difference in survival rates in early-stage patients $(\mathrm{P}=0.184)$, a trend was still observed. An increase in sample numbers may aid with the identification of an association. In addition, multivariate survival analysis demonstrated that TSP50 expression was a significant independent hazard factor for DFS in patients with NSCLC along with smoking history, pathological stage and lymphatic invasion and for OS along with pathological stage and lymphatic invasion. These results demonstrated that TSP50 has the potential to be an effective predictor of poor prognosis. To the best of our knowledge, this is the first study demonstrating that TSP50 expression is associated with clinical characteristics and poor prognosis in patients with NSCLC.

Previous studies, along with the present study, have suggested the use of TSP50 as a potential novel biomarker for the prognostic evaluation and as a potential molecular target in various types of tumors $(10,11)$. Therefore, the molecular mechanism of how TSP50 affects tumor progression needs to be understood. Zhang (22) revealed that the knockdown of TSP50 may cause the inhibition of cellular proliferation, migration, and invasion of laryngocarcinoma Hep2 cells. Yuan et al (12) reported that the overexpression of TSP50 promoted proliferation and migration of cervical cancer cells, depending on its threonine protease activity and its interactions with tumor necrosis factor- $\alpha$-induced $\mathrm{NF}-\kappa \mathrm{B}$. To delineate the involvement of TSP50 in cellular proliferation, Li et al (23) constructed and characterized a mutant TSP50 (TSP50 T310A) whose mutation significantly decreased TSP50-induced cellular proliferation in vitro and abolished the tumorigenicity of TSP50 in nude mice. These results revealed that the $\mathrm{T} 310 \mathrm{~A}$ mutation prevented interaction between TSP50 and the NF- $\mathrm{B}-\mathrm{I} \kappa \mathrm{B} \alpha$ complex, which is necessary for TSP50 to perform its function in cellular proliferation. Despite these previous studies increasing the understanding of the molecular mechanism by which TSP50 affects tumor progression, there remain multiple functions and mechanisms by which TSP50 is involved in tumorigenesis, which have not yet been elucidated. As the $\mathrm{NF}-\kappa \mathrm{B}$ pathway has been demonstrated to be associated with TSP50 in numerous tumorigenesis pathways, it has been speculated that TSP50 may perform an oncogenic function in lung tumorigenesis through similar or more complicated signaling pathways. However, additional in vitro and in vivo studies are required to clarify this.

In addition, previous results demonstrated that by enhancing tumor cell survival, CTAs may decrease the effectiveness of treatment with cytotoxic agents, indicating that CTAs may be important in treatment responses to cytotoxic or growth inhibitory anti-cancer drugs (24). As for TSP50, Zhou et al (25) reported that TSP50 encodes a Testis-Specific Protease and it is negatively regulated by p53, knockdown of TSP50 resulted in greater sensitivity to doxorubicin-induced apoptosis in P19 murine embryonal carcinoma cells and that activation of caspase-3 was involved in this process. CTAs expressed in the normal testis and in different types of human cancers not only exhibit characteristics important for tumorigenesis, but also represent promising targets for immunotherapy (20). Locally advanced, good performance status patients with NSCLC may be offered concurrent chemotherapy, radical radiotherapy and/or surgery, with a PFS rate of $\sim 8$ months and a $<15 \%$ 5-year survival rate (26). Therefore, immunotherapeutic strategies for the treatment of NSCLC are currently in clinical trials, and involve increasing tumor immunogenicity by using cancer vaccines to augment tumor-immune recognition and overcoming tumor immunosuppression by using immune checkpoint inhibitors, which demonstrated promising prospects (27). The present results demonstrated that high-level TSP50 expression was significantly correlated with late tumor status $(\mathrm{P}=0.004)$ and late pathological stage $(\mathrm{P}=0.026)$. Therefore, additional investigations to determine the prognostic value of TSP50 in other clinical settings, including advanced NSCLC treated with targeted treatments, immunotherapy, or combined with chemotherapy would facilitate clinical use of this novel protein.

In conclusion, TSP50 is overexpressed in NSCLC. The present study proposed that TSP50 may be an independent prognostic factor and a novel therapeutic target for NSCLC. Additional investigations are required to fully elucidate the specific molecular mechanisms behind the function of TSP50 in NSCLC, and to demonstrate the prognostic value of TSP50 in a clinical setting.

\section{Acknowledgements}

The authors would like to thank Dr Hua-Mei Tang and Dr Jun Lin (Department of Pathology, Shanghai First People's Hospital, Shanghai, China) for their evaluation of the IHC data.

\section{Funding}

The present study was supported by grants from The National Natural Science Foundation of China (General Program; grant no. 81372521$)$. 


\section{Availability of data and materials}

The datasets used and/or analyzed during the current study are available from the corresponding author on reasonable request.

\section{Authors' contributions}

QL, WLQ and BWS conceived and designed the experiments. WLQ and BWS performed the experiments, and BWS, YDH and $\mathrm{HYH}$ were responsible for clinical data collection and follow-up. QL, WLQ, BWS, HMT and JL analyzed the data and QL, WLQ and BWS contributed reagents, materials and analysis tools. WLQ and BWS wrote the manuscript and all authors have read and approved the final version of manuscript.

\section{Ethics approval and consent to participate}

All procedures performed were in conformity to the ethical standards of the institutional and national committee on human experimentation and with the 1964 Helsinki declaration and its later amendments. Ethical approval was given by the medical ethics committee of Shanghai First People's Hospital with the following reference number: 2013KY036.

\section{Consent for publication}

The study participants provided consent for the data to be published.

\section{Competing interests}

The authors declare that they have no competing interests.

\section{References}

1. Herbst RS, Heymach JV and Lippman SM: Lung Cancer. N Engl J Med 359: 1367-1380, 2008.

2. Torre LA, Bray F, Siegel RL, Ferlay J, Lortet-Tieulent J and Jemal A: Global cancer statistics, 2012. CA Cancer J Clin 65 : 87-108, 2015.

3. Spira A and Ettinger DS: Multidisciplinary management of lung cancer. N Engl J Med 350: 379-392, 2004.

4. Goldstraw P: The 7th edition of TNM in lung cancer: What now? J Thorac Oncol 4: 671-673, 2009.

5. Yuan LM, Shan JD, De Risi D, Broome J, Lovecchio J, Gal D, Vinciguerra V and Xu HP: Isolation of a novel gene, TSP50, by a hypomethylated DNA fragment in human breast cancer. Cancer Res 59: 3215-3221, 1999.

6. Shan J, Yuan L, Xiao Q, Chiorazzi N, Budman D, Teichberg S and Xu HP: A possible protease in human testes, is activated in breast cancer epithelial cells1. Cancer Res 62: 290-294, 2002

7. Xu H, Shan J, Jurukovski V, Yuan L, Li J and Tian K: TSP50 encodes a testis-specific protease and is negatively regulated by p53. Cancer Res 67: 1239-1245, 2007.

8. Song ZB, Bao YL, Zhang Y, Mi XG, Wu P, Wu Y, Yu CL, Sun Y, Zheng LH and Huang YX: Testes-specific protease 50 (TSP50) promotes cell proliferation through the activation of the nuclear factor $\kappa \mathrm{B}(\mathrm{NF}-\kappa \mathrm{B})$ signalling pathway. Biochem J 436: 457-467, 2011.
9. Song ZB, Ni JS, Wu P, Bao YL, Liu T, Li M, Fan C, Zhang WJ, Sun LG, Huang YX and Li YX: Testes-specific protease 50 promotes cell invasion and metastasis by increasing NF-kappaB-dependent matrix metalloproteinase-9 expression. Cell Death Dis 6: e1703, 2015.

10. Zheng L, Xie G, Duan G, Yan X and Li Q: High Expression of Testes-specific protease 50 is associated with poor prognosis in colorectal carcinoma. PLoS One 6: e22203, 2011.

11. Liu F, Cao Q, Liu N, Li C, You C, Liu C, Xue L and Luo R: Overexpression of testes-specific protease 50 (TSP50) predicts poor prognosis in patients with gastric cancer. Gastroenterol Res Pract 2014: 498246, 2014.

12. Yuan J, Wu C, Huang M, Zhou J, Ben W and Zhang G: TSP50 depends on its threonine protease activity and its interactions with TNF- $\alpha$-induced NF- $\mathrm{BB}$ for its role in human cervical tumorigenesis. Cell Biochem Biophys 71: 891-896, 2015.

13. Maggiore C, Mulè A, Fadda G, Rossi ED, Lauriola L, Vecchio FM and Capelli A: Histological classification of lung cancer. Rays 29: 353-355, 2004.

14. Wang M, Bao YL, Wu Y, Yu CL, Meng XY, Huang YX, Sun Y, Zheng LH and Li YX: Basic FGF Downregulates TSP50 expression via the ERK/Sp1 Pathway. J Cell Biochem 111: 75-81, 2010.

15. Song ZB, Liu B, Li YY, Wu P, Bao YL, Huang YX, Wu Y, Sun LG Yu CL, Sun Y, et al: The catalytic triad of testes-specific protease 50 (TSP50) is essential for its function in cell proliferation. Cell Signal 26: 2266-2275, 2014.

16. Wei J, Liu Y, Yang S, Xu J, Kong H, Han B, Bao Y, Wu Y, Yin W, $\mathrm{Li} \mathrm{W}$, et al: Screening of single-chain variable fragments against TSP50 from a phage display antibody library and their expression as soluble proteins. J Biomol Screen 11: 546-552, 2006.

17. Liu YL and Sun YN: Down-regulation of testes-specific protease 50 induces apoptosis in human laryngocarcinoma HEp2 cells in a NF-кB-mediated pathway. Mol Biol 41: 7743-7747, 2014.

18. Kosaka-Suzuki N, Suzuki T, Pugacheva EM, Vostrov AA, Morse HC III, Loukinov D and Lobanenkov V: Transcription factor BORIS (Brother of the Regulator of Imprinted Sites) directly induces expression of a cancer-testis antigen, TSP50, through regulated binding of BORIS to the Promoter. J Biol Chem 286: 27378-27388, 2011.

19. Cheng YH, Wong EW and Cheng CY: Cancer/testis, (CT) antigens, carcinogenesis and spermatogenesis. Spermatogenesis 1: 209-220, 2011

20. Kim YD, Park HR, Song MH, Shin DH, Lee CH, Lee MK and Lee SY: Pattern of cancer/testis antigen expression in lung cancer patients. Int J Mol Med 29: 656-662, 2012.

21. Grah JJ, Katalinic D, Juretic A and Santek F and Samarzija M: Clinical significance of immunohistochemical expression of cancer/testis tumor-associated antigens (MAGE-A1, MAGE-A3/4, NY-ESO-1) in patients with non-small cell lung cancer. Tumori 100: 60-68, 2014.

22. Zhang XP: Depression of testes-specific protease 50 (TSP50) inhibits cell proliferation and induces apoptosis in laryngocarcinoma. Tumour Biol 35: 10781-10788, 2014.

23. Li YY, Bao YL, Song ZB, Sun LG, Wu P, Zhang Y, Fan C, Huang YX, Wu Y, Yu CL, et al: The threonine protease activity of testes-specific protease 50 (TSP50) is essential for its function in cell proliferation. PLoS One 7: e35030, 2012.

24. Gjerstorff MF, Andersen MH and Ditzel HJ: Oncogenic cancer/testis antigens: Prime candidates for immunotherapy. Oncotarget 6: 15772-15787, 2015.

25. Zhou L, Bao YL, Zhang Y, Wu Y, Yu CL, Huang YX, Sun Y, Zheng LH and Li YX: Knockdown of TSP50 inhibits cell proliferation and induces apoptosis in P19 cells. IUBMB Life 62: 825-832, 2010.

26. Molina JR, Yang P, Cassivi SD, Schild SE and Adjei AA: Non-small cell lung cancer: Epidemiology, risk factors, treatment, and survivorship. Mayo Clin Proc 83: 584-94, 2008.

27. Mostafa AA and Morris DG: Immunotherapy for lung cancer: Has it finally arrived? Front Oncol 4: 288, 2014. 